\title{
SOBRE A CONSTITUIÇÃO E DESENVOLVIMENTO DA LEGISLAÇÃO ESPORTIVA DE FLORIANÓPOLIS (1986 - 2015)
}

Recebido em: 14/12/2017

Aceito em: 20/09/2018

Verônica Werle Universidade Federal do Paraná (UFPR) ${ }^{1}$

Curitiba - PR - Brasil

Alexandre Fernandez $\mathrm{Vaz}^{2}$

Universidade Federal de Santa Catarina (UFSC)

Florianópolis - SC - Brasil

RESUMO: Este trabalho teve como objetivo e analisar a trajetória recente das políticas públicas esportivas de Florianópolis. Trata-se de uma pesquisa descritiva e exploratória com análise dos dispositivos legais que versam sobre a organização, estrutura e funcionamento destas políticas entre os anos de 1986 a 2015. O texto é organizado em três partes correspondentes a períodos temporais delimitados em função do conteúdo dos documentos e da instituição da Fundação Municipal de Esportes. Observam-se cenários de intensa disputa política ao longo do tempo. Os mecanismos legais mesmo os mais democráticos, não foram capazes de efetivar maior equidade valorativa do esporte e do lazer em todas as suas dimensões. As ações direcionadas ao fortalecimento do esporte de rendimento amador perpetuam-se.

PALAVRAS CHAVE: Política Pública. Esportes. Atividades de Lazer. Florianópolis.

\section{ON THE CONSTITUTION AND DEVELOPMENT OF LAWS OF SPORTS IN FLORIANÓPOLIS (1986 - 2015)}

ABSTRACT: This paper analyses the recent sports policies of Florianopolis. This is an exploratory research with analysis of the legal provisions about organization, structure and operation of these policies between 1986 and 2015. It presents three sections according to the different periods and to the content of the documents and the institution of the Sports Municipal Foundation. Scenarios of intense political debate were observed. The legal mechanisms, even the most democratic, were not able to carry higher equity evaluative sport and leisure in all its dimensions. The actions of strengthening the sport "amateur" perpetuate themselves.

KEYWORDS: Public Policy. Sports. Leisure Activities. Florianopolis.

\footnotetext{
${ }^{1}$ Docente da Universidade Federal do Paraná.

${ }^{2}$ Docente da Universidade Federal de Santa Catariana. Pesquisador do 1C do CNPq.
} 


\section{Introdução}

Com a realização dos conhecidos megaeventos esportivos no Brasil intensificam-se pesquisas e estudos sobre eles, muitas vezes com foco de análise no legado, o que não é pouco, embora as análises sistemáticas sobre a constituição e desenvolvimento histórico-social das políticas públicas de esporte e lazer continuem demandando mais investigação. O fato de o país sediar esses eventos expressa uma mentalidade há muito gestado no interesse governamental, crente na coincidência entre êxitos esportivo, social e político de um país.

Para além da necessária continuidade e aprofundamento teórico que os estudos sobre as políticas públicas de esporte e lazer no Brasil precisam empreender (SUASSUNA, 2007; MEZZADRI, 2011), também é fundamental o desenvolvimento de pesquisas nos âmbitos municipais e estaduais, tendo em vista as particularidades e especificidades locais. Como observa Menicucci (2008), a ausência de princípios e orientações nacionais que efetivem o esporte e o lazer como direitos faz com que governos locais estabeleçam diretrizes próprias e muitas vezes de forma frágil.

Diferentemente do que acontece na Educação e na Saúde que possuem Sistemas Nacionais, o setor esportivo brasileiro, sempre foi organizado de forma independente nos diferentes âmbitos estatais e mesmo com a elaboração de um Sistema Brasileiro do Desporto $^{3}$, a desarticulação, pelo menos em relação à prática desportiva não formal ${ }^{4}$,

\footnotetext{
${ }^{3}$ Embora já se tenha estabelecido diversas composições do Sistema Brasileiro do Desporto, a construção de um sistema, tendo em vista as inter-relações entre seus membros e sua estrutura organizacional iniciou-se no interior das Conferências Nacionais do Esporte (2004, 2006 e 2010), quando foi aprovada a Resolução de Criação do Sistema Nacional de Esporte e Lazer e deliberadas propostas para quatro eixos, quais sejam: Estrutura: organização, agentes e competências; Recursos Humanos e Formação; Gestão e Controle Social e, Financiamento.

${ }^{4} \mathrm{Se}$ as práticas desportivas formais forem consideradas intimamente relacionadas ao esporte de rendimento já que se caracterizam por "aquelas reguladas por normas nacionais e internacionais e pelas regras de prática desportiva de cada modalidade", então se vê que estão em um nível organizacional superior às práticas não-formais, pois constituem um sistema próprio dentro do Sistema Brasileiro, nomeado Sistema Nacional do Desporte. (Lei 9.615, de 24 de março de 1998).
} 
permanece. Os sistemas de desporto dos Estados, do Distrito Federal e dos Municípios, seguem sendo organizados de forma autônoma e em regime de colaboração com o nacional, sendo desprezada a necessidade de que se estabeleçam diretrizes sobre as responsabilidades e competências mínimas às três esferas públicas sobre as políticas esportivas. Se, por um lado, isso permitiu uma maior flexibilidade para que cada instituição pública construísse políticas que reconheçam as especificidades da cultura corporal de sua região, por outro, a inexistência de orientações gerais e dispositivos legais, contribuiu, de modo geral, para a descontinuidade das ações, com a prevalência de políticas de governo no lugar de políticas de Estado, e permitiu que os interesses da sociedade fossem interpretados e direcionados a legitimar projetos de manutenção de poder estatal, ou reduzidos a benefícios de grupos consolidados ou particulares. Concordamos, no entanto, que a construção das políticas de esporte e lazer não se dá sem interações e disputas de poder (MEZZADRI, 2011) e, por isso mesmo, a sistematização de diretrizes pode contribuir na condução de políticas esportivas nacionais e locais com a garantia mínima dos princípios da descentralização e da democracia.

A falta de diretrizes e requisitos mínimos fixados em lei não significa que não possa haver programas e projetos esportivos bem-sucedidos, educacionais, participativos ou de rendimento. Observa-se, no entanto, que um modelo mais ou menos comum às gestões públicas da área foi construído em correspondência com projetos políticos e sociais de cada governo, mas também com representações hegemônicas sobre esporte e lazer em cada período histórico. Neste sentido, este texto objetiva apresentar a trajetória das políticas públicas esportivas e de lazer de Florianópolis, 
capital de Santa Catarina, analisando dispositivos legais, especialmente aqueles que dizem respeito à constituição da Fundação Municipal de Esportes (FME).

Podemos considerar que os órgãos e instituições públicas esportivas de Santa Catarina, tanto estaduais quanto municipais, têm sido pouco investigados, pelo menos quando comparados a outros estados brasileiros, a exemplo dos estudos de Mezzadri; Cavichiolli e Souza (2006) e de Motta e Terra (2011). Destacam-se, no entanto, alguns trabalhos importantes. Em relação às políticas da esfera estadual, as análises têm se voltado aos Jogos Abertos de Santa Catarina (JASC), criados em 1960, principal competição poliesportiva do Estado. Vaz (2001), por exemplo, analisa a relação das políticas esportivas com a tradição autoritária do Brasil e, com base na observação de uma tendência, reflete sobre a hegemonia do JASC e a repercussão disso na organização do esporte e lazer dos municípios catarinenses. Livros com análises sobre a cobertura jornalística dos JASC (PIRES, 2008), e sobre a relação entre a Fundação Catarinense de Esporte (FESPORTE) e os JASCs (MENDES; SOUZA; CASTRO, 2008), também contribuem. Em relação à esfera municipal, há trabalhos sobre o governo da Frente Popular em Florianópolis (1993-1996). Um deles discute sobre os fundamentos que poderiam sustentar uma gestão democrática e popular do esporte pela FME e aponta algumas possibilidades de programas e ações que possibilitariam o acesso democrático à cultura corporal (VAZ, 1994). O outro analisa concepções que orientaram a formulação das políticas públicas de lazer daquele governo, verificando avanços e descompassos entre as propostas e ações empreendidas (CRUZ, 1999). Um terceiro, mais recente, procurou compreender como as questões de gênero estão incorporadas (ou não) nas políticas públicas de esporte e lazer da FME, mostrando como a valorização diferenciada das modalidades e dimensões esportivas, a ausência de políticas de lazer e 
a naturalização de aspectos de gênero contribuem para a manutenção de "políticas generificantes" (WERLE, 2011).

Embora estes estudos pontuais contribuam para o debate e as reflexões, ainda são necessárias pesquisas com análises mais detalhadas sobre a elaboração das políticas, seu financiamento, as estruturas organizacionais internas, a gestão dos recursos humanos e materiais, bem como a história das instituições e órgão esportivos dos municípios e do estado catarinense, a fim de poder-se compreender as reais dimensões e repercussões das políticas de esporte e lazer adotadas. Sendo assim, este trabalho procura traçar e analisar a trajetória da legislação relacionada ao esporte em nível municipal no período de 1986 a 2015, a fim de identificar no texto jurídico princípios norteadores e indicativos da institucionalização do esporte e do lazer em Florianópolis.

A opção pela análise dos documentos oficiais neste primeiro esforço de construção de uma trajetória das políticas municipais da FME tem relação com a ausência, quase absoluta, de registros públicos sobre as propostas e ações, seja do governo atual ou em administrações anteriores ${ }^{5}$. Ainda que tais documentos não expressem o que teria acontecido, dizem sobre os discursos oficiais, as intenções, mesmo que muitas vezes não implementadas. Além disso, constituem-se em fonte importante para entendermos as concepções e ações cristalizadas no presente, bem como o jogo político que compõe as decisões oficiais.

A pesquisa realizada é predominantemente exploratória, considerando o pouco conhecimento a respeito do objeto em estudo, cujo ponto de partida foi o acesso ao

\footnotetext{
${ }^{5}$ No site da FME, há pouco mais que informações incompletas sobre algumas ações, link para quatro leis e um comentário sobre a sua instituição em 1987. Disponível em: http://www.pmf.sc.gov.br/entidades/esportes/ Também não há arquivos disponíveis para consulta como informaram os atuais funcionários da FME.
} 
sistema de busca on-line do site da Câmara Municipal de Florianópolis ${ }^{6}$. Tendo como filtro as palavras "esporte", "esportivo" e "lazer", foram encontrados aproximadamente 126 documentos. Entre estes, foram descartados documentos que se referiam a declarações de utilidade pública ${ }^{7}$ concedidas a associações e grêmios recreativos de bairros, torcidas organizadas, entre outras entidades; documentos que instituem datas comemorativas alusivas a pratica esportiva ${ }^{8}$, assim como aqueles em que as palavras da busca apareciam de forma generalizada, a reboque de outros termos como educação e cultura, como os convênios celebrados pelas áreas de Saúde e Assistência Social. A partir destes critérios de exclusão, foram selecionados 11 documentos que remetiam diretamente a organização, estrutura e funcionamento da política de esporte e de lazer de Florianópolis, conforme quadro a seguir:

Quadro 1: Legislação referente à política de esporte e de lazer de Florianópolis.

\begin{tabular}{l|l}
\hline \multicolumn{1}{c|}{ Lei/Ano } & \multicolumn{1}{c}{ Descrição } \\
\hline $\begin{array}{l}\text { Lei no } 2600 \text { de } 16 \text { de junho de } 1987 \\
\text { Lei Orgânica do Município de Florianópolis de } 5 \\
\text { de abril de } 1990 \\
\text { Lei } 410930 \text { de julho de } 1993\end{array}$ & $\begin{array}{l}\text { Institui a Fundação Municipal de Esportes. } \\
\text { Lei Orgânica Municipal. }\end{array}$ \\
Lei 4277 de 22 de dezembro de 1993 & $\begin{array}{l}\text { Dispõe sobre o estímulo as atividades esportivas, a } \\
\text { criação de campos para a prática de futebol pela } \\
\text { comunidade e dá outras providências }\end{array}$ \\
& $\begin{array}{l}\text { Dispõe sobre benefícios fiscais aos contribuintes } \\
\text { que incentivarem o desporto e as atividades }\end{array}$ \\
Lei 434728 de março de 1994 & $\begin{array}{l}\text { Cria polos desportivos nos distritos da ilha de } \\
\text { Lei } 4858 \text { de } 24 \text { de abril } 1996\end{array}$ \\
$\begin{array}{l}\text { Santa Catarina } \\
\text { Dispõe sobre a obrigatoriedade do poder público } \\
\text { municipal conceder o uso das quadras de esporte } \\
\text { das escolas da rede municipal de ensino para as } \\
\text { comunidades nas quais estão inseridas }\end{array}$
\end{tabular}

\footnotetext{
${ }^{6}$ Site da Câmara Municipal de Florianópolis: https://www.cmf.sc.gov.br/.

${ }^{7}$ No contexto investigado foram encontradas 85 declarações de utilidade pública. São elas um título concedido a entidades privadas, sem fins lucrativos, que prestam serviços de interesse para a coletividade, e atuam em diferentes áreas como educação, esporte, cultura, entre outras. No entanto, segundo Marin (1996, p. 42), em muitas situações, a concessão deste título tem sido realizada de forma indiscriminada a entidades de fins mais ou menos públicos, propiciando "um livre campo às concessões de caráter pessoal, de agrados políticos".

${ }^{8}$ Uma destas datas comemorativas é, por exemplo, o Dia do Treinador Esportivo (FLORIANÓPOLIS, 2010).
} 
Lei 194 de 9 de setembro de 1997

Lei 7279 de 14 de março de 2007

Lei 8090 de 21 de dezembro de 2009

Lei 9040 de 14 de setembro de 2012

Lei 9936 de 11 de dezembro de 2015
Concede isenção de tributos municipais às entidades desportivas sediadas em Florianópolis e dá outras providências

Dispõe sobre a política municipal de esporte.

Dispõe sobre a criação, composição, competência e funcionamento do conselho municipal de esporte e lazer.

Cria o sistema desportivo municipal de Florianópolis e dá outras providências

Institui no município de Florianópolis o programa bolsa desportiva municipal.

Fonte: site da Câmara Municipal de Florianópolis. Autoria própria

Para contextualizar histórica e politicamente os documentos analisados, bem como buscar compreender o conjunto de forças mobilizadas em torno do esporte e do lazer, também recorremos aos Projetos de Lei e Atas de Sessão da Câmara de Vereadores referentes às leis supracitadas. Estes documentos, ausentes online foram disponibilizados, em cópia, pelo Setor de Arquivo da Câmara de Vereadores de Florianópolis e serão devidamente referenciados no decorrer do texto. O processo de seleção e posterior análise se deram à luz das orientações de Cellard (2008), que destaca a necessidade de relacionar elementos do quadro teórico com o contexto histórico de produção dos documentos, a identificação socio-política de seus autores e respectivos interesses, além do reconhecimento da lógica interna do texto documental. Sem a pretensão de uma análise aprofundada das diferentes gestões municipais envolvidas na construção dos documentos analisados, muito mesmo a de contar uma história oficial, nossa intenção é mostrar tendências gerais e destacar indicações e pistas que ajudem a entender o desenvolvimento do setor público esportivo em Florianópolis, a partir da perspectiva regulatória.

O texto segue organizado em três partes ordenadas por critérios temporais, antes das considerações finais. A primeira apresenta o processo de "Transformação do CME em FME”, tendo em vista o cenário político presente entre os anos de 1986 e 1987. A 
seguinte, intitulada "Entre a solidificação da política do esporte 'amador' e iniciativas democráticas”, compreende o período de 1988 a 2006, quando foi verificada a primeira onda de documentos relativos ao setor esportivo. Na terceira parte, relativa ao período de 2007 a 2015, é apresentada a distância "Entre os avanços legais e a implementação das políticas esportivas", quando foi verificada uma segunda onda regulatória relacionada ao esporte no município.

\section{A Transformação do CME em FME (1986 - 1987)}

A FME foi instituída em 1987 (FLORIANÓPOLIS, 1987a, doravante FL), sendo a primeira estrutura própria a gerir o esporte em Florianópolis, sucedendo o então Conselho Municipal do Esporte (CME) criado em 1976 e vinculado, inicialmente à Secretaria Municipal de Educação, Saúde e Assistência Social ${ }^{9}$.

Entre as limitadas informações disponíveis no site da Fundação, está indicado que nenhum representante de entidades ligadas ao esporte aceitara o convite de assumir o então Conselho de Esporte no início da gestão do Prefeito Édison Andrino de Oliveira e vice-prefeito Pedro Medeiros, ambos do PMDB, em 1986, em função da falta de dotaçao orçamentária própria para a instituição. A partir deste impasse um grupo de pessoas, sob o apelo do prefeito da época, teria começado a examinar a questão e formulado a criação da FME.

Em outubro daquele ano, o prefeito encaminhou à Câmara Municipal um Projeto de Lei solicitando a instituição da Fundação, bem como da Fundação Municipal de Cultura e da Empresa Municipal de Turismo (FL, 1986a). Além da necessidade de estrutura própria para estes setores (na época, todos vinculados a Secretaria de

\footnotetext{
${ }^{9}$ Embora a delimitação temporal deste estudo inicie em 1986, cabe a ressalva de que ainda antes do CME, um outro órgão havia sido responsável pelo setor esportivo municipal, a Comissão Municipal de Esportes, criada em 1961, e subordinada diretamente ao Gabinete do Prefeito.
} 
Turismo), o Projeto foi justificado pelos benefícios que o formato de Fundação, no lugar de Secretarias ou Departamentos, proporcionaria especificamente no que se refere a maior autonomia financeira e agilidade organizacional. Informação pouco conhecida, que consta no documento é que além do Conselho Municipal de Esporte (CME), responsável pelas "atividades no campo do esporte competitivo", a Fundação abarcaria a Divisão de Esportes, responsável pelo "esporte de lazer". (FL, 1986a). O desconhecimento de tal fato deve-se ao envolvimento prioritário do município com iniciativas de desenvolvimento do esporte de rendimento amador, mesmo antes da FME e do CME, quando, por meio de uma Comissão Municipal de Esporte, mobilizava-se para a participação nos Jogos Abertos de Santa Catarina (JASC) ${ }^{10}$, desde a primeira edição, em 1960.

O Projeto fora encaminhado um mês antes da segunda eleição direta para o Governo do Estado, já na fase de transição democrática pós-ditadura, em um contexto de confrontos e embates peculiares ao momento político pelo qual passava a cidade e o Estado. Naquelas eleições cinco candidatos estavam na disputa, entre eles Pedro Ivo Campos de Figueiredo (PMDB), candidato do partido do prefeito da capital e seu apoiador durante as eleições municipais no ano anterior, e Amilcar Gazaniga (PDS), lançado pelo então governador do Estado Esperidião Amin.

A polarização da disputa entre o PDS e o PMDB no âmbito estadual já havia se dado nas primeiras eleições diretas na capital um ano antes, na qual Andrino (PMDB)

\footnotetext{
${ }^{10}$ Os Jogos Abertos de Santa Catarina (JASC) acontecem desde 1960, inspirados nos Jogos Abertos do Interior, do interior de São Paulo e fruto da iniciativa do desportista Arthur Schlösser. Com a amplitude e abrangência tomada, os Jogos passam a ser organizados pela FESPORTE a partir de 1993. Nas duas primeiras edições dos Jogos, Florianópolis foi campeã, sendo que em 1961 também foi anfitriã, recebendo os Jogos na cidade.
} 
saíra vencedor. ${ }^{11}$ Os reflexos desta disputa também eram visíveis na ocasião da apreciação do Projeto de criação da FME na Câmara Municipal. Entre votos favoráveis de vereadores da "situação", que supostamente favoreceria o PMDB nas eleições estaduais, e os votos contrários da bancada de "oposição", o Projeto foi rejeitado no cômputo final, em um movimento que demonstra a relevância dos setores esportivos e culturais para o fortalecimento de grupos políticos partidários.

Conforme consta em Ata da Sessão realizada em 19 de novembro, o vereador Michel Curi justifica o voto contrário da bancada do PDS “por entender que o Chefe do Poder Executivo cometeu uma deselegância para com a Câmara Municipal, mandando este Projeto com prazo, em um mês de eleição, quando sete Srs. Vereadores eram candidatos". (FL, 1986b, p. 4). Este e outros vereadores acrescentam, posteriormente, que a rejeição também se devia à necessidade de maior detalhamento e prazo para a proposta ser analisada. Entre os que eram favoráveis, o vereador Sérgio Grando, afirmou que "os companheiros que votaram contra este Projeto não analisaram no sentido do que poderia vir para o município, mas no sentido político partidário. Respeito o voto dos companheiros, mas sinto que o município perdeu” (FL, 1986b, p. 4).

O caráter político envolvido no período de tentativa de instituição da Fundação Municipal de Esporte é comprovado pela aprovação unânime do Projeto assim que passadas as eleições estaduais, na qual saiu vitorioso Pedro Ivo Campos (PMDB). Ainda no primeiro semestre pós-eleições, novo Projeto de Lei foi encaminhado para a Câmara Municipal, desta vez solicitando a criação da FME separadamente da Fundação de Cultura (FL, 1987b). Tendo sido apresentadas e discutidas algumas emendas pelos vereadores e com parecer de aprovação das comissões técnicas da câmara (de Finanças,

\footnotetext{
${ }^{11}$ Sobre os contextos, as candidaturas e os resultados das disputas eleitorais de Florianópolis entre 1985 e 2008, consultar Carreirão (2009).
} 
de Justiça e Comissão de Educação, Cultura, Esporte e Turismo), que não tiveram tempo para se posicionarem na ocasião anterior, a instituição da Fundação foi aprovada. Em Ata da Sessão do dia 1 de junho de 1987a, aparece a citação do vereador César Fontes destacando, em nome da bancada do PDS, a ampla discussão que o Projeto passou para que fosse aprovado. (FL, 1987b, p. 5).

De modo geral poucas foram as mudanças realizadas no Projeto original. As emendas apresentadas pelos vereadores foram inclusões de termos e expressões no sentido de melhorar a redação e evitar futuros problemas jurídicos. Ainda foram acrescidos o "Quadro de Pessoal" proposto para a Fundação e a obrigatoriedade em remeter semestralmente à Câmara relatório técnico e financeiro. O que fica evidente é o jogo político marcado pelo esforço de uma aprovação rápida por um lado e uma rejeição pouco fundamentada de outro, aspecto que revela "marcas de nossa herança patrimonialista e também do populismo e personalismo tão presentes na história política brasileira", como afirmam Linhales et al. (2008, p.18), ao se referirem às políticas públicas de esporte e lazer nos municípios brasileiros.

Como pode ser verificado no documento final, na forma da Lei 2600 de 16 de junho de 1987 (FL, 1987a), a preocupação inicial foi a estruturação administrativa da Fundação, especialmente em relação à constituição do seu patrimônio, dos recursos humanos e financeiros, da utilização e exploração dos implementos esportivos, e das formas de parcerias entre entidades públicas e privadas, favorecidas pela então recémpublicada Lei Sarney ${ }^{12}$, como citado no Projeto de Lei (FL, 1987b). O item "financiamento" foi central para a instituição da Fundação, tendo em vista que, naquele momento, seu formato oferecia as condições jurídicas necessárias para a captação de

12 A Lei Sarney, instituída em 1986 foi a primeira a proporcionar incentivo fiscal aos doadores e patrocinadores de atividades culturais. Ela foi revogada em 1990 e seus princípios restituídos um ano depois sob a forma da Lei Rouanet (BRASIL, 1991). 
recursos financeiros diretamente na forma de convênios. Um exemplo é o Recriança ${ }^{13}$, programa da Secretaria de Assistência Social do Ministério da Previdência implementado em Florianópolis na década de 1980, com objetivo de atender crianças e jovens no contraturno escolar a partir da oferta de atividades esportivas e culturais.

Neste sentido, a instituição da Fundação foi, certamente, um avanço em relação ao antigo Conselho, pois o novo órgão passou a ter infraestrutura própria de recursos humanos, financeiros e materiais. Por outro lado, o documento pouco avançou na delimitação de objetivos e finalidades relacionadas aos elementos e dimensões da cultura corporal. O objetivo da FME é apresentado como sendo "executar a política de esportes do Município de Florianópolis, formulada pela Secretaria Municipal de Turismo, Cultura e Esportes". Além disso, o esporte só volta a aparecer de forma muito genérica no segundo artigo, parágrafos II e V, em se lê que caberia à Fundação "organizar e desenvolver programas esportivos" e "exercer quaisquer outras atividades relacionadas com o esporte e a educação física, compatíveis com suas finalidades". Apesar da redação limitada do documento, com a criação da Fundação, pautava-se a necessidade de ampliação dos serviços públicos relacionados ao esporte. Para além do desenvolvimento do esporte competitivo, característica do CME, era preciso incluir suas dimensões participativa e escolar, mesmo que muito discretamente, como relataram alguns funcionários que participaram desta transição (WERLE, 2011), estas dimensões, assim como o termo lazer não aparecem na redação do documento, mostrando uma lacuna importante, tendo em vista que sua presença na legislação constitui-se num primeiro passo para a distribuição de recursos e execução de políticas públicas que

\footnotetext{
${ }^{13}$ Sobre o programa vale consultar a excelente análise de Zaluar (1991).
} 
oferecessem diferentes formas de manifestações esportivas e de ocupação do tempo livre.

Ainda que uma política esportiva possa ser orientada pela dimensão participativa, indicando o esporte como possibilidade de lazer, entende-se que este pode envolver também expressões corporais e artísticas. A despeito da funcionalização e comercialização do lazer, em que este se configura como uma forma de controle e disciplinamento do trabalhador após a jornada laboral e/ou de experiências de consumo de mercadorias, ele pode se constituir como um tempo/espaço privilegiado de produção, transformação e apropriação crítica da cultura. Sejam pela intervenção das/nas próprias manifestações culturais, ou por meio da reflexão dos valores e sentidos intrínsecos a elas, as práticas de lazer podem se configurar em "possibilidade ética e estéticas de humanização se realizad[as]os e praticad[as]os como experiências educativas capazes de promover a emancipação e não a barbárie” (ISAYAMA; LINHALES, 2006, p. 10). A ampliação destas possibilidades de lazer implica na organização de políticas públicas específicas para o setor, que visem garanti-lo como direito social.

\section{Entre a Solidificação da Política do Esporte “Amador" e Iniciativas Democráticas (1988 - 2006)}

Dos quase vinte anos que seguiram à instituição da FME, entre 1988 a 2006, encontramos poucos registros legais no sentido de uma maior organização ou sistematização das políticas esportivas e de lazer no município pela Fundação, observando-se, porém, uma onda de iniciativas legais relacionadas especialmente à garantia de espaços físicos para as práticas.

A referência mais significativa ao setor, neste período, é sua citação na Lei Orgânica Municipal (LOM). A LOM é a principal forma de manifestação da autonomia 
municipal introduzida pela Constituição de 1988, tendo importante papel histórico, pois consiste na primeira vez em que, no "constitucionalismo brasileiro, o Município passou a integrar efetivamente a Federação, dispondo de poderes próprios assegurados no texto constitucional da mesma forma que a União e os Estados Federados" (RESENDE, 2008, p. 11). Além disso, sabe-se da relevância dessa Constituição no que se refere à incorporação de direitos fundamentais, incluindo o esporte e o lazer, na agenda pública federal, levando com que, gradativamente, estados e municípios também passassem a se comprometer com a inclusão e democratização de tais práticas (LINHALES et al., 2008). Esta é a tendência observada na LOM de Florianópolis, instituída em 1990, em que se vê um primeiro esforço na especificação quanto às atribuições do setor esportivo e a contemplação legal das dimensões do esporte educacional e do lazer:

Art. 126 - O Município fomentará as práticas desportivas formais e não formais, promovendo medidas que assegurem, prioritariamente: I - desenvolvimento do desporto educacional e amador; II - criação de espaços públicos destinados à prática do esporte; III - incentivo às competições desportivas locais e microrregionais; IV - incentivo ao esporte de cunho comunitário e de lazer (FL, 1990).

Sendo a LOM responsável por fixar as atribuições, obrigações e competências do poder público local, é a partir dela que as políticas da FME deveriam se orientar inicialmente. Diz-se "inicialmente" porque, ainda que fosse o que de mais esclarecedor houvesse à época, delimitações específicas sobre as possibilidades de operacionalização e execução do que está legalmente instituído são igualmente necessárias sob pena das orientações constantes da LOM não terem qualquer aplicação prática. Ainda que falte ao texto maior correspondência com o contexto cultural municipal, por exemplo, com as práticas corporais de origem açoriana, as medidas de valorização de espaços e competições locais, seu teor democrático e descentralizador, refletem as mudanças ocorridas na Constituição, não apenas com a inclusão do esporte e do lazer como 
direitos sociais, mas com a consolidação do entendimento sobre as dimensões educativas, participativas e de rendimento do esporte por meio do fomento das práticas esportivas formais e não-formais e da priorização do esporte educacional (TUBINO, 2010, p. 29). ${ }^{14}$

Para além da LOM, identificou-se a criação de diversos mecanismos legais relacionados ao esporte, por meio de propostas encaminhadas pelo setor legislativo. Entre eles estão a criação e manutenção de áreas destinadas à prática de futebol e atividades correlatas, observando-se a distribuição entre as regiões da cidade e o livre acesso da população (FL, 1993a); a criação de polos nos distritos do município com a finalidade desenvolver a prática desportiva com orientação profissional e especializada (FL, 1994); a concessão do uso das quadras de esporte das escolas da rede municipal de ensino para as comunidades nas quais estão inseridas (FL, 1996), o que é reforçado anos depois quando são disponibilizadas as instalações físicas internas e externas das mesmas escolas municipais para atividades de esporte, cultura e lazer.

Por meio destes dispositivos verifica-se a tentativa de amenizar um problema central ligado às políticas públicas de esporte e lazer, que é o espaço físico para desenvolvimento das atividades e para livre uso da população. Estes espaços constituem-se, segundo Rechia e França (2006, p. 73) “o próprio pulsar da vida urbana”, sendo alternativas às práticas de lazer de caráter funcionalistas e consumistas, centradas na necessidade de satisfação imediata e permanente. Embora não sejam de simples execução, entendemos que os documentos acima referenciados encaminharam

\footnotetext{
${ }^{14}$ A ampliação do conceito de esporte no Brasil a partir do delineamento das dimensões esportivas, já havia sido indicada em 1985 pela Comissão de Reformulação do Esporte Brasileiro, presidida por Manoel Tubino, mas só ganhou especificidade legal e conceitual com a Lei Zico (Lei nº 8.672/1993) (TUBINO, 2010).
} 
alternativas com maiores chances de aplicação porque se referem a espaços públicos já existentes.

Outro aspecto importante refere-se ao financiamento. Ainda, em 1993 é aprovada a lei 4277 que dispõe sobre benefícios fiscais aos contribuintes que incentivarem o desporto e as atividades desportivas (FL, 1993b). Embora não estivesse assim nomeada, esta lei contém os princípios das atuais Leis de Incentivo à Cultura e Leis de Incentivo ao Esporte. O conteúdo do documente estabelece que todo o gerenciamento do processo (do cadastro das entidades esportivas interessadas na contribuição à certificação dos contribuintes) ficaria a cargo da FME, porém não indica como seria a administração desses recursos, tampouco onde estariam alocados. Assim como em cidades paranaenses com o mesmo tipo de lei, segundo Mezzadri; Cavichiolli e Souza (2006), em Florianópolis ela jamais foi efetivada, algo que pode ser também atribuído à descontinuidade da gestão, cujo movimento pode ser verificado no desenvolvimento do texto.

Esta primeira onda de ampliação dos instrumentos legais no campo esportivo concretizou-se na gestão da Frente Popular (1993-1996), liderada pelo prefeito Sérgio Grando, do Partido Popular Socialista (PPS) ${ }^{15}$. Durante ela foram desenvolvidas pela FME políticas que incluíam as dimensões esportivas do lazer e das práticas culturais locais, como evidenciados por Cruz (1999). Apesar do caráter democrático visualizado nos documentos e na bibliografia, o esporte de rendimento continuou tendo espaço privilegiado na FME durante esta gestão, como acontecia mesmo antes do Conselho Municipal de Esporte (CME), e quando paulatinamente observa-se a subordição das

\footnotetext{
${ }^{15}$ Conforme explica Carreirão (2009, p. 41), para sua candidatura e gestão, Sérgio Grando "conseguiu nuclear uma grande coligação, incluindo todos os partidos de esquerda relevantes, mais o PSDB. O candidato a vice-prefeito seria Afrânio Boppré, do PT.”
} 
ações da Fundação ao sistema esportivo organizado pelo Estado ${ }^{16}$. Em mensagem publicada no boletim InformAção, o prefeito da época não deixou dúvidas sobre o papel da FME na formação das equipes municipais e da sua função de representar e qualificar o município por meio da sua participação nos JASC:

Florianópolis disputará, no esforço de cada um dos 150 atletas que integram nossa delegação, mais um Jogos Abertos de Santa Catarina, na cidade de Tubarão. Espero que o empenho da administração municipal, traduzida no trabalho da Fundação Municipal de Esportes em oferecer as melhores condições de infraestrutura, reflita numa colocação honrosa para nosso município. Estaremos competindo em 19 modalidades com a esperança de bons resultados, capazes de garantir à Capital um posto entre os cinco melhores municípios de Santa Catarina nos JASC. Confio no potencial de cada um dos nossos atletas, principalmente, no investimento que a Fundação Municipal de Esportes vem fazendo nas categorias de base [...]

Prefeito Municipal de Florianópolis. Sérgio José Grando (InformAção, nov. 1993, apud Cruz, 1999).

Ainda que tenha perdurado a tradição da primazia do investimento e das políticas no esporte competitivo, os documentos analisados mostram avanços em relação à tentativa de construção de instrumentos legais com foco em práticas corporais que atendessem interesses culturais diversos e em maior abrangência do território municipal, tanto por iniciativa do poder legislativo, quanto do Executivo.

Nos anos que se seguiram, no entanto, não foram identificadas ações no sentido da permanência ou ampliação das propostas originárias no período de gestão da Frente Popular, mas de intensificação ainda maior no incremento do esporte de alto rendimento, muitas vezes nomeado como esporte "amador". Nos documentos da FME, verifica-se o uso indiscriminado para os termos esporte amador, de rendimento ou

\footnotetext{
${ }^{16} \mathrm{O}$ sistema esportivo organizado pelo Estado de Santa Catariana compreende um conjunto de eventos organizados pela FESPORTE, entre os quais, além dos Jogos Abertos de Santa Catarina (JASC), fazem parte os Joguinhos Abertos, o Para-JASC, os Jogos Escolares de Santa Catarina (JESC) e a Olimpíada Estudantil de Santa Catarina (OLESC), demandando e permitindo um envolvimento estável e vigoroso dos municípios catarinenses, inclusive "[d] aqueles de pequeno porte e limitado poder econômico, pela regionalização das suas diversas etapas" (PIRES, BIANCHI; BITENCOURT, 2010, p. 39).
} 
competitivo. No entanto, eles parecem se referir especialmente aos esportes que têm a função de "representar" o município em competições estaduais e nacionais, em especial nos JASC. Além disso, o próprio JASC é classificado como esporte de rendimento, embora "o discurso midiático apresent[e]-o como um encontro do esporte amador, com exceção do Futebol" (MENDES; SOUZA: CASTRO, 2008, p. 44). Por isso e tendo em vista a Lei 9.615/1998, que prevê a possibilidade da prática do esporte de rendimento na forma não profissional, consideramos mais adequado o termo esporte de rendimento amador. Tal aspecto pode ser verificado pelos altos investimentos do Executivo nesta dimensão esportiva (WERLE, 2011), na concessão de isenção de pagamento de tributos municipais para entidades desportivas amadoras (FL, 1997), conforme proposta do legislativo, inicialmente vetada ${ }^{17}$ pela prefeita Ângela Amin (1997 - 2000 e 2001 2004), do Partido Popular (PP), bem como pela retomada do município às primeiras posições no JASC, sendo campeão em 2001 e 2002, depois de 40 anos sem conquistar o almejado título ${ }^{18}$. A exemplo, de como ocorre no estado do Paraná, que também organiza seus Jogos Abertos, (MEZZADRI; CAVICHIOLLI; SOUZA, 2006), o evento catarinense é central para a definição das políticas municipais no estado, “Afinal, diz o imaginário presente em Santa Catarina, as Fundações Municipais, ou outros órgãos gestores do esporte, têm a sua eficiência e eficácia julgadas justamente pelo poder de fogo nas competições, levando às manchetes de jornal o nome do município” (VAZ, 2001, p. 93).

\footnotetext{
${ }^{17}$ Conforme consta no processo referente à lei (FL, 1997), o referido veto deu-se com base em parecer técnico do setor financeiro, que alegou que tal iniciativa favoreceria um setor da sociedade em detrimento dela como um todo, com prejuízos financeiros ao município. O veto foi rejeitado pela Câmara, que alegou o amplo interesse público que as ações das entidades esportivas amadoras propiciavam.

${ }^{18}$ Desde a criação dos Jogos em 1960, Florianópolis foi campeã em 1960, 1961, 2001, 2002, e entre 2009 e 2012, tendo sido vice-campeã em outras 11 ocasiões.
} 


\section{Entre os Avanços Legais e a Implementação das Políticas Esportivas (2007 - 2015)}

A partir de 2007 foi identificada uma segunda onda de criação de mecanismos legais relacionados ao esporte e ao lazer em Florianópolis. Diferentemente da primeira onda, mais pontual e voltada para a descentralização de serviços e espaços destinados às práticas corporais, o movimento no âmbito jurídico observado entre 2007 e 2015 foi de caráter mais amplo, na direção da consolidação de diretrizes e orientações da política setorial esportiva.

Assim, em 2007, foi aprovada a Política Municipal de Esporte (FL, 2007) e posteriormente o Sistema Desportivo Municipal (FL, 2012), ambas as propostas originárias do setor legislativo, de autoria de partidos de oposição e objetos de embates políticos durante os governos de Dário Berger (2005-2008, PSDB, e 2009-2012, PMDB).

O documento que estabelece a Política Municipal de Esporte, bem mais completo que os anteriores, ampliam as competências da Fundação, incluindo como finalidade a garantia de acesso a projetos de lazer, o desenvolvimento das ciências do esporte e a qualificação dos recursos humanos, mantendo também os objetivos de aprimoramento das equipes e atletas do município. Apesar de estarem em parágrafo à parte, o esporte educacional, a promoção social e as práticas esportivas não profissionais também são contempladas. Chama a atenção o equilíbrio entre todas as dimensões esportivas, a atribuição inusitada e inadequada, a nosso ver, da produção do conhecimento científico da área da Educação Física/Ciência do Esporte ao executivo municipal, bem como o destaque a princípios e diretrizes voltadas à gestão e ao controle democrático, inclusive com a constituição de um Conselho Municipal, órgão colegiado normativo e consultivo da política municipal. Este parece ter sido um aspecto decisivo 
para o veto do prefeito da época. Baseado nos pareceres do então superintendente e do assessor jurídico da FME, a proposta fora negada pelo Executivo, pois pouco inovaria em relação ao que já era realizado pela FME, porque "causaria ingerência" da instituição ao propor a criação de um Conselho, sendo este "um entrave burocrático". Por fim, os pareceres encaminhados pelo prefeito apontam que tal projeto "foi motivado por pessoas desconhecedoras da política e estrutura administrativa já existente no Município. Estão sendo redundantes. Estão apenas querendo conquistar mais poderes em prejuízo do esporte e da comunidade.” (FL, 2006).

Assim como aconteceu em relação à Política Municipal de Esportes, o processo de aprovação do Sistema Desportivo Municipal (FL, 2012) sofreu veto do prefeito, sendo este, por sua vez, rejeitado pela Câmara. Além de serem identificadas as instituições pertencentes ao sistema, o documento também reforça a instituição do Conselho e determina os seus membros, incluindo representantes de entidades acadêmicas, de setores públicos como educação e saúde, sindicatos, atletas, para-atletas, árbitros e treinadores. Embora se observe a diversidade institucional dos atores, é evidente a ausência de representantes de práticas informais, por exemplo, associações de bairros, ONGs etc., os quais poderiam potencializar iniciativas relacionadas ao esporte de participação, entre outras práticas de lazer. Mas, contrariando uma suposta negligência em relação à dimensão participativa do esporte, o item relacionado ao financiamento da FME estabelece que seja destinado quarenta por cento dos recursos ao esporte educacional e atividades recreativas e de lazer, trinta por cento à organização e realização de eventos esportivos locais e iguais montantes ao esporte de rendimento, visando a representação da cidade em competições estaduais e nacionais. $\mathrm{O}$ veto do prefeito à criação do Sistema foi igualmente baseado na ingerência que o projeto 
causaria, interferindo na independência dos poderes, além de gerar aumento de despesas, avaliadas como inviáveis, à FME.

Os processos de criação das leis acima citadas evidencia que o aparato jurídico tem sido visto pelo Executivo como instrumento negativo de intervenção no trabalho do setor esportivo. Ao que parece, no lugar de diretrizes para a condução mais transparente das políticas setoriais, tem-se suposto que a legislação ocasione perda de autonomia e do poder real e simbólico da administração do setor. Se por um lado, o jogo político permite que tal situação possa se concretizar, por outro é preciso questionar a ausência de propostas encaminhadas pelo Executivo. No caso de Florianópolis, a negligência dos gestores em estabelecerem parâmetros legais para o desenvolvimento das políticas esportivas converte-se em uma luta contra aqueles que se ocupam desta função, dificultando o protagonismo dos chamados "técnicos" ou "especialistas" na elaboração da legislação de sua própria área. Para, além disso, fica evidente a resistência apresentada aos mecanismos de participação popular visto como "inimigos" dos gestores também em outros casos investigados (STAREPRAVO, 2007). Isso se expressa nas diversas tentativas de implementação do Conselho Municipal de Esporte, elemento presente tanto na Política e no Sistema Desportivo Municipal, como em legislação específica que o institui (FL, 2009), embora jamais tenha sido implementado. Ambas as medidas, a criação do Conselho e a destinação de recursos para diferentes dimensões das práticas corporais, são essenciais para a inclusão de interesses de grupos diversos nas agendas governamentais, possibilitando a melhor adequação das políticas às necessidades e direitos de jovens e idosos, homens e mulheres, atletas e praticantes informais, entre tantos. $\mathrm{O}$ maior contato dos gestores com a realidade, o conhecimento dos interesses e aspirações da sociedade e atendimento às suas reivindicações, podem 
contribuir na diminuição das tendências em valorizar preferências pessoais e políticas que historicamente tiveram a presença hegemônica do esporte de alto rendimento.

A última legislação de destaque relacionada à área esportiva foi a instituição do Programa Bolsa Desportiva Municipal, em 2015 (FL, 2015), a única encaminhada pelo Executivo que foi aprovada após a Lei que instituiu a Fundação em 1987. O programa destina-se a apoiar financeiramente atletas, para-atletas, técnicos e auxiliares, participantes tanto do esporte educacional como do de alto rendimento. Assim como inclui o esporte educacional, o texto também aborda objetivos relacionados ao incentivo de "jovens valores" e à "promoção social" por meio do esporte. Ao mesmo tempo e contraditoriamente, aponta que a prioridade são os atletas de modalidades nas quais "o Município vem apresentando melhor desempenho técnico", determinando como critério de classificação para recebimento da bolsa a obtenção da primeira à terceira colocação em eventos esportivos oficiais. O programa claramente atende às demandas por atletas que representem o município ao obrigar que o requerente represente "o município de Florianópolis em todas as competições que a Fundação Municipal de Esportes for participante e desejar convocá-lo.”. O pagamento de bolsas, embora tardiamente oficializado, é uma prática recorrente no Estado. Assim como apontou Vaz (2001) em relação à contratação de atletas de outras cidades ou estados, a institucionalização das bolsas aponta tanto um pesado investimento com fim de obtenção de bons resultados nos JASC, como também revelam estruturas profissionais precárias, que negligenciam o acesso mínimo aos direitos trabalhistas por parte de atletas e técnicos. O documento que institui o Programa é claro quando aponta que o pagamento da bolsa "não gera vínculo laboral ou de qualquer natureza com a administração pública municipal nem com a 
Fundação Municipal de Esportes, sendo que o valor pago possui caráter indenizatório". (FL, 2015).

No campo jurídico-esportivo, a segunda onda regulatória municipal apresenta importante avanço na garantia de participação em manifestações diversas das práticas esportivas e de lazer, dos espaços físicos, da presença popular e dos mecanismos de controle sociais, em direção à construção de políticas que podem vir a se consolidar como de Estado.

\section{Considerações Finais}

A construção e análise da trajetória das políticas públicas esportivas de Florianópolis por meio dos documentos legais, especialmente no que se refere à Fundação Municipal de Esportes, permitiu vislumbrar um cenário de intensas disputas no qual se deu a transformação do CME em FME, bem como as demais tentativas de organizar ou estabelecer diretrizes para o setor esportivo na cidade.

Por um lado, grande parte do discurso oficial apresentado nos documentos ainda não foi traduzida em medidas e ações efetivas, especialmente no que se refere aos mecanismos de gestão e participação popular. Por outro lado, ações direcionadas ao fortalecimento do esporte de rendimento amador, tendo em vista sua função de representação do município em competições de repercussão estadual e nacional, como o Programa Bolsa Desportiva Municipal ${ }^{19}$, ganharam efetividade com maior facilidade. Isso indica que há um processo arbitrário de seleção dos artigos e leis aos quais

\footnotetext{
${ }^{19}$ No ano seguinte a oficialização do Programa, foram contempladas 186 pessoas, entre atletas, para atletas e técnicos. Informação presente no site na Fundação, pelo link https://www.pmf.sc.gov.br/entidades/esportes/?pagina=notpagina\&menu=3\&noti=17045
} 
interessa seguir para a manutenção do poder estatal, a despeito do emprego integral ou homogêneo do que está legalmente instituído.

Tal situação se perpetua, em grande medida, porque a avaliação da administração municipal dos esportes dependente dos resultados e classificações das suas equipes, tornando imperativo que quase todo o investimento seja direcionado ao chamado esporte de rendimento amador. Assim sendo, a sistematização legal de diretrizes de caráter mais democrático e descentralizado não foram capazes de promover uma "virada" efetiva no sentido de maior equidade financeira e valorativa do esporte e do lazer em todas as suas dimensões.

Por fim, considera-se que a trajetória apresentada e as reflexões empreendidas significam apenas uma fração da realidade ou uma perspectiva de análise sobre as intervenções públicas no e pelo esporte em Florianópolis. Todavia procurou-se construir um registro capaz de dar visibilidade para a temática proposta, podendo ser considerado um ponto de partida que, certamente, convida a outros estudos a partir de distintas fontes, como os documentos jornalísticos, imagens e personagens que possam compor novos cenários, vindo a confirmar, contestar ou relativizar as reflexões aqui empreendidas.

\section{REFERÊNCIAS}

BRASIL. Lei 8313, de 23 de dezembro de 1991. Lei Rouanet. Restabelece princípios da Lei 7505, de 2 de junho de 1986. Institui o Programa nacional da Cultura (Pronac) e dá outras providências. Brasília: DF, 1991.

CARREIRÃO, Yan de Souza. As eleições para prefeito em Florianópolis: contribuição para uma história eleitoral. Perspectivas, São Paulo, v. 35, p. 35-62, jan./jun. 2009.

CELLARD, André. A análise documental. In: POUPART, Jean et al. A pesquisa qualitativa: enfoques epistemológicos e metodológicos. Petrópolis: Vozes, 2008. p. 295-316. 
CRUZ, Manoel Luís Martins da. Políticas públicas de lazer em Florianópolis: um estudo das propostas da frente popular. 1999. 135 f. Dissertação (Mestrado)Universidade do Estado de Santa Catarina, Mestrado em Educação e Cultura, 1999.

FLORIANÓPOLIS. Lei 9936 de 11 de dezembro de 2015. Institui no município de Florianópolis o programa bolsa desportiva municipal. Florianópolis: Câmara Municipal de Florianópolis, 2015.

Lei 9040 de 14 de setembro de 2012. Cria o sistema desportivo municipal de Florianópolis e dá outras providências. Florianópolis: Câmara Municipal de Florianópolis, 2012.

. Lei 8281 de 16 de junho de 2010. Instituí no município de Florianópolis o dia 20 de setembro como o Dia do Treinador Esportivo. Florianópolis: Câmara Municipal de Florianópolis, 2010.

Lei 8090 de 21 de dezembro de 2009. Dispõe sobre a criação, composição, competência e funcionamento do conselho municipal de esporte e lazer. Florianópolis: Câmara Municipal de Florianópolis, 2009.

Lei 7279 de 14 de março de 2007. Dispõe sobre a política municipal de esporte. Florianópolis: Câmara Municipal de Florianópolis, 2007.

. Parecer referente ao Projeto de Lei 11.973 de 2006. Parecer de Pedro Teixeira, Assessor Jurídico da FME, encaminhado a Câmara Municipal em 30 de novembro de 2006. Florianópolis: Câmara Municipal de Florianópolis, 2006.

Lei 194 de 9 de setembro de 1997. Concede isenção de tributos municipais às entidades desportivas sediadas em Florianópolis e dá outras providências. Florianópolis: Câmara Municipal de Florianópolis, 1997.

Lei 4858 de 24 de abril 1996. Dispõe sobre a obrigatoriedade do poder público municipal conceder o uso das quadras de esporte das escolas da rede municipal de ensino para as comunidades nas quais estão inseridas. Florianópolis: Câmara Municipal de Florianópolis, 1996.

Lei 434728 de março de 1994. Cria polos desportivos nos distritos da ilha de Santa Catarina. Florianópolis: Câmara Municipal de Florianópolis, 1994.

. Lei 4277 de 22 de dezembro de 1993. Dispõe sobre benefícios fiscais aos contribuintes que incentivarem o desporto e as atividades desportivas. Florianópolis: Câmara Municipal de Florianópolis, 1993b.

Lei 410930 de julho de 1993. Dispõe sobre o estímulo as atividades esportivas, a criação de campos para a prática de futebol pela comunidade e dá outras providências. Florianópolis: Câmara Municipal de Florianópolis, 1993a.

FLORIANÓPOLIS. Lei Orgânica do Município de Florianópolis de 5 de abril de 1990. Lei Orgânica Municipal. Florianópolis: Câmara Municipal de Florianópolis, 1990. 
. Ata da $41^{\mathrm{a}}$ Sessão Ordinária, do $5^{\circ}$ período Legislativo, da $10^{\mathrm{a}}$ Legislatura, realizada no dia 1 de junho de 1987c. Florianópolis: Câmara Municipal de Florianópolis, $1987 \mathrm{c}$.

Projeto de Lei $\mathbf{n}^{\mathbf{0}}$ 3.374. Institui a Fundação Municipal de Esporte. Câmara Municipal de Florianópolis, 1987 b.

Lei $\mathbf{n}^{\mathbf{0}} \mathbf{2 6 0 0}$ de 16 de junho de 1987. Institui a Fundação Municipal de Esportes. Florianópolis: Câmara Municipal de Florianópolis, 1987a.

Ata da Sessão Extraordinária, realizada no dia 19 de novembro de 1986. Florianópolis: Câmara Municipal de Florianópolis, $1986 \mathrm{~b}$.

Projeto de Lei no 3.207. Institui a Fundação Municipal de Cultura, a Fundação Municipal de Esportes e a empresa Municipal de Turismo. Câmara Municipal de Florianópolis, 1986a.

ISAYAMA, Hélder Ferreira; LINHALES, Meily Assbú Linhales. Apresentação. In:ISAYAMA, Hélder Ferreira; LINHALES, Meily Assbú Linhales (Org.) Sobre lazer e politica: maneiras de ver, maneiras de fazer. Belo Horizonte: Editora UFMG, 2006. $165 \mathrm{p}$.

LINHALES, Meily A. et al. Esporte e lazer na Grande-BH: por onde caminham as gestões públicas. In: ISAYAMA, Hélder; LINHALES, Meily (Org.). Avaliação de políticas e políticas de avaliação: questões para o esporte e o lazer. Belo Horizonte: Ed UFMG, 2008. p. $13-57$.

MARIN, Eriberto F. Entidade de utilidade pública: efeitos jurídicos de sua declaração. Revista da Faculdade de Direito UFG, v.19/20, n.1, p. 39-46, jan./dez.1996.

MENICUCCI, Telma. Políticas de esporte e lazer: o estado da arte e um objeto em construção. In: ISAYAMA, Hélder; LINHALES, Meily (Org.). Avaliação de políticas e políticas de avaliação: questões para o esporte e o lazer. Belo Horizonte: Ed UFMG, 2008.p. 179-202.

MEZZADRI, Fernando M.; CAVICHIOLLI, Fernando Renato; SOUZA, Doralice Lange de (Org.). Esporte e Lazer: subsídios para o desenvolvimento e a gestão de políticas públicas. Jundiaí: Fontoura, 2006.

. Políticas públicas para o esporte e lazer: teorias e conceitos. In: MOTTA, Alexandre; TERRA, Rodrigo (Org.). Esporte, lazer e políticas públicas na Região dos Lagos. Rio de Janeiro: Ventura, 2011.

MENDES, Diego S; SOUZA, Daniel M.; CASTRO Huáscar S. O esporte “amador" em Santa Catarina: a Fesporte e o JASC. In: PIRES, Giovani D.L. (org.) et al. Observatório da Mídia Esportiva: a cobertura jornalística dos jogos abertos de Santa Catarina. Florianópolis: Nova Letra, 2008.

MOTTA, Alexandre; TERRA, Rodrigo (Org.). Esporte, lazer e políticas públicas na Região dos Lagos. Rio de Janeiro:Ventura, 2011. 
PIRES, Giovani D.L. (org.) et al. Observatório da Mídia Esportiva: a cobertura jornalística dos jogos abertos de Santa Catarina. Florianópolis: Nova Letra, 2008.

RECHIA, Simone. FRANÇA, Rodrigo. O Estado do Paraná e seus espaços e equipamentos de esporte e lazer: apropriação, desapropriação ou reapropriação? In: MEZZADRI, Fernando M.; CAVICHIOLLI, Fernando Renato; SOUZA, Doralice Lange de (Org.). Esporte e Lazer: subsídios para o desenvolvimento e a gestão de políticas públicas. Jundiaí: Fontoura, 2006.

RESENDE, Antônio J. C. Autonomia Municipal e Lei orgânica. Cad. Esc. Legisl., Belo Horizonte, v. 10, n. 15, p. 7-42, jan./dez. 2008

STAREPRAVO Fernando. A. Políticas públicas para o esporte e lazer: conselhos municipais de esporte e lazer e outras formas de participação direta. In: CONGRESSO BRASILEIRO DE CIÊNCIAS DO ESPORTE, 15 e CONGRESSO INTERNACIONAL DE CIÊNCIAS DO ESPORTE, 2. Anais... Recife: CBCE, 2007. Disponível em: https://www.cbce.org.br/cd. Acesso em: 10 mai. 2009. p.1-9.

SUASSUNA, Dulce et al. O Ministério do Esporte e a definição de políticas para o lazer. In: SUASSUNA, Dulce; AZEVEDO, Aldo. Política e Lazer: Interfaces e perspectivas (Org.). Brasília, Thesaurus, 2007. p. 13-42.

TUBINO. Manoel J. G.. Estudos brasileiros sobre o esporte: ênfase no esporteeducação. Maringá: Eduem, 2010.

VAZ Alexandre F. Políticas públicas para o esporte e o lazer em Santa Catarina: reflexões e considerações. Revista da Educação Física/UEM. Maringá, v. 12, n. 1, p. 89-96, 1. sem. 2001.

. Fundação Municipal de Esportes na gestão da Frente Popular: contribuições ao debate. Motrivivência. Dezembro, n. 5, p.93-96, 1994.

WERLE, Verônica. Questões de gênero nas políticas públicas de esporte e lazer da Fundação Municipal de Esportes de Florianópolis. 150 p. Dissertação (Mestrado) Universidade Federal de Santa Catarina, Centro de Desportos, Programa de PósGraduação em Educação Física, Florianópolis, 2011.

ZALUAR, Alba. O esporte na educação e na política pública. Educação \& Sociedade. Abril, n. 38, p. 19-44, 1991.

\section{Endereço dos Autores:}

Verônica Werle

DTPEN/Setor Educação/UFPR

Rua General Carneiro, 460 - Edifício D. Pedro I - $2^{\circ}$ andar

Curitiba - Paraná - 80.060-150

Endereço Eletrônico: vewerle@yahoo.com.br 


\author{
Alexandre Fernandez Vaz \\ $\mathrm{EED} / \mathrm{CED} / \mathrm{UFSC}$ \\ Campus Universitário (Trindade) \\ Florianópolis - SC - 88040-900 \\ Endereço Eletrônico: alexfvaz@uol.com.br
}

